\title{
PENERAPAN MODEL DESAIN INSTRAKSIONAL DICK AND CAREY DALAM PEMBELAJARAN MATEMATIKA KELAS VIII SEMESTER GENAP SMP PADA MATERI BANGUN RUANG SISI DATAR.
}

\author{
Penulis \\ : Ghufron Kamil \\ Institusi \\ : Magister Teknologi Pendidikan Universitas Muhammadiyah Jakarta \\ Email Korespondensi : ust.ghufron@gmail.com \\ DOI \\ : https://doi.org/10.53947/perspekt.v1i1.24
}

Kata Kunci:

Model Dick Dan Carey

Desain Instraktional

Model Pembelajaran

Matematika
Keywords:

Model Dick and Carey Instructional Design

Learning model

Mathematics

\begin{abstract}
Abstrak
Dengan daya saing yang semakin lama semakin ketat. Peserta didik dituntut untuk menguasai berbagai macam ketrampilan. Hanya dengan pengalaman belajar yang baik dan suasana belajar yang kondusiflah peserta didik dapat lebih mudah untuk mendapatkan kemampuan yang dibutuhkan dalam persaingan dimasa yang akan datang. Untuk itu guru juga dituntut untuk dapat menghadirkan semua kebutuhan peserta didik tersebut. Agar tujuan pembelajaran dapat tercapai dengan baik. Dick dan Carey memasukkan unsur kognitif dan behavioristik yang menekankan pada respon peserta didik terhadap stimulus yang dihadirkan. Implementasi model desain sistem pembelajaran ini memerlukan proses yang sistematis yang menyeluruh. Hal ini diperlukan untuk dapat menciptakan desain sistem pembelajaran yang mampu digunakan secara optimal dalam mengatasi masalah-masalah pembelajaran.
\end{abstract}

\begin{abstract}
Students are required to master a variety of skills. Only with a good learning experience and a conducive learning atmosphere will it be easier for students to gain the skills needed in future competitions. For this reason, every teacher is required to present all the needs of students so that learning objectives can be adequately achieved. Dick and Carey include cognitive and behavioristic elements that emphasize the student's response to the stimulus presented. The implementation of this learning system design model requires a comprehensive systematic process. It is necessary to create a learning system design that can be used optimally in overcoming learning problems.
\end{abstract}

\section{PENDAHULUAN}

Pendidikan berfungsi membantu manusia

keluar sebagai pemenang dalam perkembangan kehidupan dan persaingan dalam penyempurnaan hidup lahir dan batin antar bangsa. Dengan daya saing yang semakin lama semakin ketat. Peserta didik dituntut untuk menguasai berbagai macam keterampilan. Hanya dengan pengalaman belajar yang baik dan suasana belajar yang kondusiflah peserta didik dapat lebih mudah 
untuk mendapatkan kemampuan yang dibutuhkan dalam persaingan di masa yang akan datang. Untuk itu guru juga dituntut untuk dapat menghadirkan semua kebutuhan peserta didik tersebut agar tujuan pembelajaran dapat tercapai dengan baik. Salah satu caranya adalah dengan melaksanakan proses pembelajaran yang menyenangkan dan tidak membosankan.

Damayanti dkk (2020: 3-4) menyatakan bahwa "Faktor yang menjadi penyebab dalam kejenuhan belajar meliputi metode pembelajaran yang digunakan guru tidak disukai oleh peserta didik, media pembelajaran yang kurang mendukung dalam proses pembelajaran, terlalu banyak hafalan, tugas-tugas (PR), dan tekanan dari mata pelajaran dari guru lainnya, serta saat mengajar guru terlalu monoton kepada peserta didik tanpa adanya relaksasi dalam belajar sehingga peserta didik cepat merasa bosan dan tidak bersemangat untuk mengikuti kegiatan pembelajaran."

Pembelajaran yang terstruktur dan terencana dengan baik akan menghasilkan proses belajar mengajar yang baik pula. Oleh karenanya penting bagi guru untuk merencanakan dan merancang pembelajaran secara sistematik, sistemik, logik, efisien, dan efektif. Hasil dari merancang pembelajaran adalah tersusunnya sebuah sistem pembelajaran. Suradika dkk (2020: 1028 ) menyatakan bahwa sistem pembelajaran adalah seperangkat unsur-unsur yang saling berinteraksi dan saling bergantung satu sama lain dalam upaya memfasilitasi pembelajaran untuk tercapainya tujuan pembelajaran. Terdapat sejumlah model perancangan pembelajaran, salah satunya adalah desain pembelajaran model Dick and Carey.
Dick dan Carey memasukkan unsur kognitif dan behavioristik yang menekankan pada respon peserta didik terhadap stimulus yang dihadirkan. Implementasi model desain sistem pembelajaran ini memerlukan proses yang sistematis yang menyeluruh. Hal ini diperlukan untuk dapat menciptakan desain sistem pembelajaran yang mampu digunakan secara optimal dalam mengatasi masalahmasalah pembelajaran.

Artikel ini akan menguraikan bagaimana penerapan model desain pembelajaran Dick And Carey untuk mata pelajaran Matematika Kelas VIII semester genap SMP/Sederajat pada materi Bangun Ruang Sisi Datar.

\section{PEMBAHASAN}

Komponen-komponen sekaligus langkahlangkah utama dari model desain sistem pembelajaran yang dikemukakan oleh Dick dan Carey terdiri atas 10 langkah, yaitu (a) Mengidentifikasi tujuan pembelajaran, (b) Melakukan analisis instruksional, (c) Analisis Peserta didik dan Konteks, (d) Merumuskan tujuan pembelajaran khusus, (e) Mengembangkan instrument penilaian, (f) Mengembangkan strategi pembelajaran, (g) Penggunaan Bahan Ajar, (h) Merancang dan mengembangkan evaluasi formatif, (i) Melakukan revisi terhadap program pembelajaran, (j) Merancang dan mengembangkan evaluasi sumatif. Sepuluh langkah tersebut digambarkan oleh Dick dan Carey ke dalam bagan sebagaimana gambar 1 (Dick dan Carey, 2009: 136) 


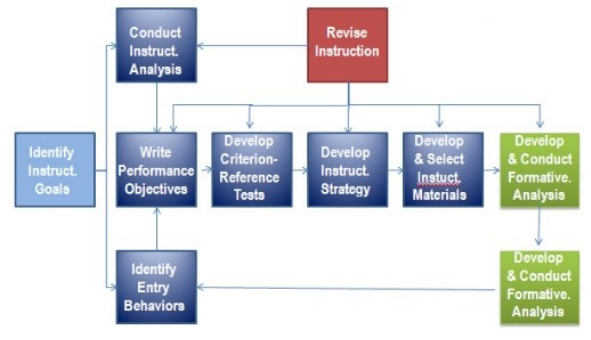

Bagan 5 Model Sistem Pembelajaran Dick Dan Carey

Langkah-langkah di atas harus dilakukan secara berurutan agar model Dick dan Carey dapat diterapkan secara ideal. berikut penjelasan dari tiap langkah:

\section{MENGIDENTIFIKASI TUJUAN PEMBELAJARAN}

Untuk mengidentifikasi tujuan pembelajaran hal yang perlu dilakukan dalam kegiatan ini adalah menentukan kemampuan atau kompetensi yang perlu dimiliki oleh peserta didik setelah menempuh program pembelajaran yang sebelumnya.istilah yang sering kita dengar adalah tujuan pembelajaran atau instructional goal. Rumusan tujuan pembelajaran dapat dikembangkan baik dari rumusan tujuan pembelajaran yang sudah ada pada silabus maupun dari hasil analisis kinerja. Rumusan tujuan pembelajaran dapat dihasilkan melalui proses analisis kebutuhan dan pengalamanpengalaman tentang kesulitan-kesulitan yang diahadapi oleh peserta didik. Selain itu tujuan pembelajaran dapat juga dirumuskan dengan menggunakan analisis tentang cara seseorang melakukan tugas atau pekerjaan yang spesifik dan persyaratan-persyaratan yang diperlukan untuk melakukan tugas dan pekerjaan tersebut, atau istilah ini disebut dengan istilah analisis tugas.

\section{MELAKUKAN ANALISIS INSTRUKSIONAL}

Setelah melakukan identifikasi tujuan pembelajaran, langkah selanjutnya adalah analisis instruksional, yaitu sebuah proses proses yang digunakan untuk menentukan keterampilan dan pengetahuan relevan dan diperlukan oleh peserta didik untuk mencapai kompetensi atas tujuan pembelajaran. Dalam melakukan analisis instruksional beberapa langkah yang diperlukan untuk mengidentifikasi kompetensi berupa pengetahuan, keterampilan dan sikap yang perlu dimiliki oleh peserta didik setelah mengikuti proses pembelajaran.

\section{ANALISIS PESERTA DIDIK DAN KONTEKS}

Dalam model Dick dan Carry analisis terhadap peserta didik yang akan belajar dan konteks pembelajaran. Kedua langkah ini dapat dilakukan secara bersama-sama atau paralel. Analisis konteks meliputi kondisikondisi terkait dengan keterampilan yang dipelajari oleh pesreta didik dan situasi yang terkait dengan tugas yang dihadapi oleh peserta didik untuk menerapkan keterampilan yang dipelajari dalam kehidupan sehari hari. Analisis terhadap karakteristik peserta didik meliputi kemampuan aktual yang yang dimiliki oleh peserta didik, gaya belajar (learning styles), dan sikap terhadap aktivitas belajar. Identifikasi yang akurat tentang karakteristik peserta didik yang akan belajar dapat membantu perancang program pembelajaran dalam memilih dan menentukan strategi pembelajaran yang akan digunakan. 


\section{MERUMUSKAN TUJUAN PEMBELAJARAN KHUSUS}

Berdasarkan analisis

instruksional, seorang perancang desain sistem pembelajaran perlu mengembangkan kompetensi atau tujuan pembelajaran spesifik (instructional objectives) yang perlu dikuasai oleh peserta didik untuk mencapai tujuan pembelajaran yang bersifat umum (instructional goal). Dalam merumuskan tujuan pembelajaran yang bersifat berspesifik, ada beberapa hal yang perlu mendapatkan perhatian: (a) Menentukan pengetahuan keterampilan yang perlu dimiliki oleh peserta didik setelah menepuh proses pembelajaran, (b) Kondisi yang diperlukan agar peserta didik dapat melakukan unjuk kemampuan dari pengetahuan yang telah dipelajari, (c) Indikator atau kriteria yang dapat digunakan untuk menentukan keberhasilan peserta didik dalam menempuh proses pembelajaran.

\section{MENGEMBANGKAN INSTRUMENT PENELITIAN}

Berdasarkan tujuan kompetensi khusus yang telah dirumuskan, langkah selanjutnya adalah mengembangkan alat atau instrumem penilaian yang mampu mengukur pencapaian hasil belajar peserta didik, hal ini dikenal dengan istilah evaluasi hasil belajar. Hal yang penting dalam menentukan instrument evaluasi yang akan digunakan adalah instrument harus dapat mengukur performance peserta didik dalam mencapau tujuan pembelajaran yang telah dirumuskan.

\section{MENGEMBANGKAN STRATEGI PEMBELAJARAN}

Strategi pembelajaran yang dapat digunakan dalam mengimplementasikan aktivitas pembelajaran yaitu aktifitas pra- pembelajaran, penyajian materi pembelajaran, dan aktivitas tindak lanjut dari kegiatan pembelajaran. Penentu strategi pembelajaran harus didasarkan pada faktorfaktor berikut: (a) Teori terbaru tentang aktifitas pembelajaran, (b) Penelitian tentang hasil belajar, (c) Karekteristik media pembelajaran yang akan digunakan untuk menyampaikan materi pembelajaran, (d) Materi atau substansi yang perlu dipelajari oleh peserta didik, (e) Karakterisitik peserta didik yang akan terlibat dalam kegiatan pembelajaran.

\section{PENGGUNAAN BAHAN AJAR}

Istilah bahan ajar sama dengan media pembelajaran, yaitu sesuatu yang dapat membawa informasi dan pesan dari sumber belajar kepada peserta didik, bahan ajar yang dapat digunakan adalah buku teks, buku panduan, modul, program audio video, bahan ajar berbasis computer, program multimedia, dan bahan ajar yang digunakan pada sistem pendidikan jarak jauh.

\section{MERANCANG DAN MENGEMBANGKAN EVALUASI FORMATIF}

Evaluasi formatif dilaksanakan untuk mengumpulkan data yang terkait dengan kekuatan dan kelemahan program pembelajaran. Hasil dari proses evaluasi formatif dapat digunakan sebagai masukan untuk memperbaiki draf program Tiga jenis evaluasi formatif:

\section{- EVALUASI PERORANGAN (ON TO ONE EVALUATION)}

Evaluasi perorangan merupakan tahap yang perlu dilakukan untuk melakukan kontak langsung dengan satu atau tiga orang calon pengguna program untuk memperoleh 
masukan tentang ketercenaan dan daya tarik program.

\section{- EVALUASI KELOMPOK SEDANG (SMALL GROUP EVALUATION)}

Evaluasi kelompok dialakukan kecil dilakukan untuk menguji cobakan program terhadap sekelompok kecil calon pengguna yang terdiri dari 10-15 orang peserta didik. Evaluasi ini dilakukan untuk memperoleh masukan yang dapat digunakan untuk memperbaiki kualitas program.

\section{- EVALUASI LAPANGAN/FIELD TRIAL}

Evaluasi lapangan adalah uji coba program sebelum program tersebut digunakan dalam situasi pembelajaran yang sesungguhnya.

\section{MELAKUKAN REVISI TERHADAP PROGRAM PEMBELAJARAN}

Langkah terakhir dari proses desain adalah melakukan revisi terhadap draf program pembelajaran. Data yang diperoleh dari prosedur evaluasi formatif dirangkum dan ditafsirkan untuk mengetahui kelemahan-kelemahan yang dimiliki oleh program pembelajaran, evaluasi tidak hanya dilakukan pada draf program pembelajaran saja, tetapi juga pada aspek-aspek desain sistem pembelajaran yang digunakan dalam program, seperti analisis instruksional, entry behavior dan karakteristik peserta didik. Prosedur evaluasi formatif perlu dilakukan pada semua aspek program pembelajaran dengan tujuan untuk memperbaiki dan meningkatkan kualitas program tersebut.

\section{MERANCANG DAN MENGEMBANGKAN EVALUASI SUMATIF.}

Evaluasi merupakan jenis evaluasi yang berbeda dengan evaluasi formatif. Evaluasi ini dianggap puncak dalam aktifitas desain pembelajaran yang dikemukakan oleh Dick dan Carrey. Evaluasi sumatif dilakukan setelah program selesai dievaluasi secara formatif dan direvisi sesuai dengan standar yang digunakan oleh perancang. Evaluasi sumatif tidak melibatkan perancang program, tetapi melibatkan penilai independen. Hal ini merupakan satu alasan untuk menyatakan bahwa evaluasi sumatif tidak tergolong kedalam proses desain sistem pembelajaran. Langkah desain pembelajaran yang dikemukakan oleh Dick dan Carrey merupakan sebuah prosedur yang menggunakan pendekatan sistem dalam mendesain sebuah program pembelajaran. Setiap langkah dalam desain pembelajaran memiliki keterkaitan antara satu dengan yang lainnya.

\section{PENERAPAN DESAIN}

INTURKSIONAL MODEL DICK DAN

CAREY PADA MATA PELAJARAN

MATEMATIKA KELAS VIII SEMESTER 2 MATERI BANGUN RUANG SISI DATAR

- MENGANALISIS

TUJUAN PEMBELAJARAN.

Pengalaman belajar yang baik dan menyeluruh adalah sesuatu yang diharapkan dalam pembelajaran. Dengan media dan metode pembelajaran yang menyenangkan diharapkan peserta didik dapat lebih termotivasi dalam belajar. Ditambah lagi kemampuan berpikir kritis yang harus dimiliki peserta didik untuk dapat bersaing dalam era globalisasi sekarang ini.

\section{- MELAKUKAN PEMBELAJARAN}

ANALISIS

Pengenalan konsep bangun ruang sisi datar melalui metode pengajaran yang menarik bagi peserta didik, misalnya melalui 
media yang dapat menstimulasi peserta didik dalam peningkatan konsep bangun ruang sisi datar. Mengingat pentingnya media dapat meningkatkan perkembangan kognitif peserta didik khususnya peningkatan konsep bangun ruang sisi datar, maka penulis berusaha mengenalkan konsep bangun ruang sisi datar dengan cara mencoba menerapkan media benda kongkrit. Media benda kongkrit adalah media yang berasal dari sekitar peserta didik yang berbentuk bangun datar, contohnya bungkus makanan atau produk yang sehari hari digunakan peserta didik yang berbentuk bangun ruang sisi datar (kubus, balok, limas, dan prisma)

\section{- MENGANALISIS PESERTA DIDIK DAN KONTEKS}

Peserta didik pada usia SMP sangat butuh bimbingan dari guru untuk menemukan dan mengarahkan cara berpikir. Karena pada usia ini penting bagi seorang guru menanamkan rasa tanggung jawab, kemandirian, gotong royong dan mengasah berbagai jenis kecerdasan peserta didik. Sifat malas dan putus asa harus dihilangkan di ubah menjadi rasa ingin tahu dan ingin selalu mencoba hal hal baru.

Dalam materi bangun ruang sisi datar peserta didik memerlukan keterampilan ketrampilan tersebut. Pada materi ini peserta didik dapat dilatih kemampuan berpikir kritis matematik dengan beberapa indikator sebagai berikut :

Tabel 23 Keterampilan Berpikir Kritis

\begin{tabular}{|l|l|c|}
\hline $\begin{array}{l}\text { Keteram } \\
\text { pilan } \\
\text { Berpikir } \\
\text { Kritis }\end{array}$ & Indikator & Penjelasan \\
\hline $\begin{array}{l}\text { Memberi } \\
\text { kan } \\
\text { penjelasa }\end{array}$ & Memfokuska & $\begin{array}{c}\bullet \text { Mengidentifika } \\
\text { si anyaan. } \\
\text { merumuskan }\end{array}$ \\
\hline
\end{tabular}

\begin{tabular}{|c|c|c|}
\hline \multirow[t]{3}{*}{$\begin{array}{l}\mathrm{n} \\
\text { sederhana }\end{array}$} & & $\begin{array}{l}\text { pertanyaan. } \\
\text { - Mengidentifika } \\
\text { si kriteria- } \\
\text { kriteria untuk } \\
\text { mempertimban } \\
\text { gkan yang } \\
\text { mungkin. } \\
\text { - Menjaga } \\
\text { kondisi pikiran. }\end{array}$ \\
\hline & $\begin{array}{l}\text { Menganalisis } \\
\text { argument }\end{array}$ & $\begin{array}{l}\text { - Mengidentifika } \\
\text { si kesimpulan } \\
\text { - Mengidentifika } \\
\text { si alasan(sebab) } \\
\text { yang } \\
\text { dinyatakan(eks } \\
\text { plisit) } \\
\text { - Mengidentifika } \\
\text { si alasan(sebab) } \\
\text { yang tidak } \\
\text { dinyatakan(imp } \\
\text { lisit) } \\
\text { - Mengidentifika } \\
\text { si } \\
\text { ketidakrelevana } \\
\text { n dan } \\
\text { kerelevanan } \\
\text { - Mencari } \\
\text { persamaan dan } \\
\text { perbedaan } \\
\text { - Mencari } \\
\text { struktur suatu } \\
\text { argument } \\
\text { - Merangkum }\end{array}$ \\
\hline & $\begin{array}{l}\text { Bertanya dan } \\
\text { menjawab } \\
\text { pertanyaan } \\
\text { klasifikasi } \\
\text { dan } \\
\text { pertanyaan } \\
\text { yang } \\
\text { menentang }\end{array}$ & $\begin{array}{l}\text { - Mengapa } \\
\text { - Apa intinya, } \\
\text { apa artinya } \\
\text { - Apa contohnya, } \\
\text { apa yang bukan } \\
\text { contoh } \\
\text { - Bagaimana } \\
\text { menerapkannya } \\
\text { dalam kasus } \\
\text { tersebut } \\
\text { - Perbedaan apa } \\
\text { yang } \\
\text { menyebabkann } \\
\text { ya } \\
\text { - Akankah andah } \\
\text { menyatakan } \\
\text { lebih dari itu }\end{array}$ \\
\hline $\begin{array}{l}\text { Membang } \\
\text { un } \\
\text { keterampi } \\
\text { lan dasar }\end{array}$ & $\begin{array}{l}\text { Mempertimb } \\
\text { angkan } \\
\text { kredibilitas } \\
\text { (kriteria) } \\
\text { suatu sumber }\end{array}$ & $\begin{array}{l}\text { - Ahli } \\
\text { - Tidak ada } \\
\text { konflik internal } \\
\text { - Kesepakatan } \\
\text { antar sumber } \\
\text { - Reputasi } \\
\text { - Mengurutkan } \\
\text { prosedur yang }\end{array}$ \\
\hline
\end{tabular}




\begin{tabular}{|c|c|c|}
\hline & & $\begin{array}{l}\text { ada } \\
\text { - Mengetahui } \\
\text { resiko } \\
\text { - Kemampuan } \\
\text { memberi alasan } \\
\text { - Kebisaaan hati- } \\
\text { hati }\end{array}$ \\
\hline & $\begin{array}{l}\text { Mengobserva } \\
\text { si dan } \\
\text { mempertimb } \\
\text { angkan hasil } \\
\text { observasi }\end{array}$ & $\begin{array}{l}\text { - Ikut terlibat } \\
\text { dalam } \\
\text { menyimpulkan } \\
\text { - Dilaporkan oleh } \\
\text { pengamat } \\
\text { sendiri } \\
\text { - Mencatat hal- } \\
\text { hal yang } \\
\text { diinginkan } \\
\text { - Penguatan(coll } \\
\text { aboration) dan } \\
\text { kemungkinan } \\
\text { penguatan } \\
\text { - Kondisi akses } \\
\text { yang baik } \\
\text { - Penggunan } \\
\text { teknologi yang } \\
\text { kompeten } \\
\text { - Kepuasan } \\
\text { observer atas } \\
\text { kredibilitas } \\
\text { kriteria }\end{array}$ \\
\hline \multirow{3}{*}{$\begin{array}{l}\text { Menyimp } \\
\text { ulkan }\end{array}$} & $\begin{array}{l}\text { Membuat } \\
\text { deduksi dan } \\
\text { mempertimb } \\
\text { angkan hasil } \\
\text { deduksi }\end{array}$ & $\begin{array}{l}\text { - Kelompok yang } \\
\text { logis } \\
\text { - Kondisi yang } \\
\text { logis } \\
\text { - Interpretasi } \\
\text { pernyataan }\end{array}$ \\
\hline & $\begin{array}{l}\text { Membuat } \\
\text { induksi dan } \\
\text { mempertimb } \\
\text { angkan hasil } \\
\text { induksi }\end{array}$ & $\begin{array}{l}\text { - Membuat } \\
\text { gereralisasi } \\
\text { - Membuat } \\
\text { kesimpulan dan } \\
\text { hipotesis }\end{array}$ \\
\hline & $\begin{array}{l}\text { Membuat dan } \\
\text { mempertimb } \\
\text { angkan hasil } \\
\text { keputusan }\end{array}$ & $\begin{array}{l}\text { - Latar belakang } \\
\text { fakta } \\
\text { - Konsekuensi } \\
\text { - Penerapan } \\
\text { prinsip-prinsip } \\
\text { - Memikirkan } \\
\text { alternatif } \\
\text { - Menyeimbangk } \\
\text { an, } \\
\text { memutuskan }\end{array}$ \\
\hline $\begin{array}{l}\text { Membuat } \\
\text { penjelasa } \\
\mathrm{n} \text { lebih } \\
\text { lanjut }\end{array}$ & $\begin{array}{l}\text { Mendefinisik } \\
\text { an istilah, } \\
\text { mempertimb } \\
\text { angkan } \\
\text { definisi. }\end{array}$ & $\begin{array}{l}\text { - } \text { Bentuk } \\
\text { sinonim, } \\
\text { klarifikasi, } \\
\text { rentang } \\
\text { ekspresi yang } \\
\text { sama } \\
\text { - Strategi definisi }\end{array}$ \\
\hline
\end{tabular}

\begin{tabular}{|c|c|c|}
\hline & & $\begin{array}{l}\text { (tindakan } \\
\text { mengidentifikas } \\
\text { i persamaan) } \\
\text { - Isi (content) } \\
\end{array}$ \\
\hline & $\begin{array}{l}\text { Mengidentifi } \\
\text { kasi asumsi. }\end{array}$ & $\begin{array}{l}\text { - Penalaran } \\
\text { secara implisit } \\
\text { - Asumsi yang } \\
\text { diperlukan } \\
\text { rekonstrukurusa } \\
\text { si argument } \\
\end{array}$ \\
\hline \multirow[t]{2}{*}{$\begin{array}{l}\text { Strategi } \\
\text { dan tehnik }\end{array}$} & $\begin{array}{l}\text { Memutuskan } \\
\text { suatu } \\
\text { tindakan }\end{array}$ & $\begin{array}{l}\text { - Mendefinisikan } \\
\text { masalah } \\
\text { - Menyelesaikan } \\
\text { kriteria } \\
\text { - Merumuskan } \\
\text { alternatif yang } \\
\text { memungkinkan } \\
\text { - Memutuskan } \\
\text { hal-hal yang } \\
\text { akan dilakukan } \\
\text { secara alternatif } \\
\text { - Melakukan } \\
\text { revise } \\
\text { - Memonitori } \\
\text { implementasi }\end{array}$ \\
\hline & $\begin{array}{l}\text { Berinteraksi } \\
\text { dengan orang } \\
\text { lain }\end{array}$ & \\
\hline
\end{tabular}

Terdapat lima kelompok kemampuan berpikir kritis, yaitu: (a) memberikan penjelasan sederhana (elementary clarification), (b) Membangun keterampilan dasar (basic support), (c) Membuat inferensi (inferring), (d) membuat penjelasan lebih lanjut (advanced clarification), dan (d) mengatur strategi dan taktik (strategies and tactics).

Indikator kemampuan berpikir kritis dapat diturunkan dari aktivitas kritis peserta didik, yaitu (a) Memberi pernyataan yang jelas dari setiap pertanyaan, (b) Memberi alasan, (c) Berusaha mengetahui informasi dengan baik, (d) Memakai sumber yang memiliki kredibilitas dan menyebutkannya, (e) Memperhatikan situasi dan kondisi secara keseluruhan, (f) Berusaha tetap relevan dengan ide utama, (h) Mengingat kepentingan yang asli dan mendasar, (i) 
Memberi alternative, (y) Bersikap dan berpikir terbuka, (k) Mengambil posisi ketika ada bukti yang cukup untuk melakukan sesuatu, (1) Memberi penjelasan sebanyak mungkin apabila memungkinkan, dan (m) Bersikap secara sistematis dan teratur dengan bagian-bagian dari keseluruhan masalah.

\section{- MERUMUSKAN} TUJUAN KHUSUS.

Dalam desain ini, difokuskan untuk mengukur kemampuan berpikir kritis dengan indikator berikut :

\section{- MEMFOKUSKAN PERTANYAAN}

Memfokuskan pertanyaan yang dimaksud dalam lingkup mengidentifikasi atau merumuskan masalah dan mengidentifikasi kriteria-kriteria untuk mempertimbangkan yang mungkin sehingga peserta didik bisa menjawab pertanyaan yang dimaksud.

\section{- MENGANALISIS ARGUMEN}

Menganalisis argumen dalam lingkup mengidentifikasi alasan(sebab) yang tidak dinyatakan(implisit) dan mencari persamaan serta perbedaan.

\section{- MENJAWAB PERTANYAAN YANG MENENTANG}

Menjawab pertanyaan yang menentang dalam lingkup pengetahuan peserta didik yang bisa membedakan sebab dari suatu perbedaan.

\section{- MEMBUAT DAN MEMPERTIMBANGKAN HASIL KEPUTUSAN}

Membuat dan mempertimbangkan hasil keputusan dalam lingkup dapat menerapkan prinsip-prinsip yang telah dipelajari untuk membuat keputusan dan dapat menyeimbangkan dan memutuskan menjadi suatu kesimpulan.

\section{- MENGEMBANGKAN INSTRUMEN PENILAIAN}

Dalam mengembangan instrumen penilaian, lima hal yang perlu diperhatikan, yaitu (a) Observasi, (b) Mengumpulkan data, (c) Merumuskan, (d) Menilai, dan (e) Menyimpulkan

\section{- MENGEMBANGKAN STRATEGI PEMBELAJARAN.}

Metode pembelajaran yang akan digunakan adalah metode penemuan terbimbing, di mana peserta didik akan diarahkan oleh guru langkah langkah pembelajarannya. Peserta didik akan diberikan LKS untuk pedoman arah pembelajaran. Agar pelaksanaan model penemuan terbimbing ini berjalan dengan efektif, beberapa langkah yang perlu ditempuh oleh guru matematika adalah sebagai berikut.

1) Merumuskan masalah yang akan diberikan kepada peserta didik dengan data secukupnya, perumusannya harus jelas, hindari pernyataan yang menimbulkan salah tafsir sehingga arah yang ditempuh peserta didik tidak salah.

2) Dari data yang berikan guru, peserta didik menyusun, memproses, mengorganisir, dan menganalisis data tersebut. Dalam hal ini, bimbingan guru dapat diberikan sejauh yang diperlukan saja. Bimbingan ini sebaiknya mengarahkan peserta didik untuk melangkah ke arah yang hendak dituju, melalui pertanyaan-pertanyaan, atau LKS.

3) Peserta didik menyusun konjektur (perkiraan) dari hasil analisis yang dilakukannya. 
4) Bila dipandang perlu, konjektur yang telah dibuat peserta didik tersebut di atas diperiksa oleh guru. Hal ini penting dilakukan untuk meyakinkan kebenaran perkiraan peserta didik, sehingga akan menuju arah yang hendak dicapai.

5) Apabila telah diperoleh kepastian tentang kebenaran konjektur tersebut, maka verbalisasi konjektur sebaiknya diserahkan juga kepada peserta didik untuk menyusunya. Di samping itu perlu diingat pula bahwa induksi tidak menjamin 100\% kebenaran konjektur.

6) Sesudah peserta didik menemukan apa yang dicari, hendaknya guru menyedikan soal latihan atau soal tambahan untuk memeriksa apakan hasil penemuan itu benar.

\section{- MENGEMBANGKAN MATERI PE MBELAJARAN}

Guru memiliki peran penting dalam proses belajar mengajar, namun guru bukanlah satu - satunya sumber belajar. Dengan berkembangnya teknologi dan ilmu pengetahuan, guru dapat menambahkan media pembelajaran sebagai sumber belajar lain bagi peserta didik. Pada saat guru tidak bisa menjadi sumber belajar di luar jam pelajaran di sekolah, media pembelajaran dapat menjadi sumber belajar bagi peserta didik ketika membutuhkannya. Kata media dalam bahasa arab berarti “perantara (وسائل) atau pengantar pesan dari pengirim kepada penerima”. Dalam bahasa latin media adalah bentuk jamak dari kata medium yang secara harfiah berarti perantara. Media adalah segala sesuatu yang dapat digunakan untuk menyalurkan pesan dari pengirim kepada penerima sehingga dapat merangsang fikiran, perasaan, perhatian, dan minat serta perhatian peserta didik sehingga proses pembelajaran terjadi secara baik.

Penggunaan media dalam pembelajaran berguna untuk memfasilitasi peserta didik melihat miniatur benda asli yang dipelajari. Dengan penggunaan media benda kongkrit, peserta didik mendapat proses pembelajaran secara langsung. Edgar Dale dalam buku Arief, dkk "mengklasifikasi pengalaman menurut tingkat yang paling kongkrit ke yang paling abstrak yang dikenal dengan nama kerucut pengalaman (Cone of experience)".

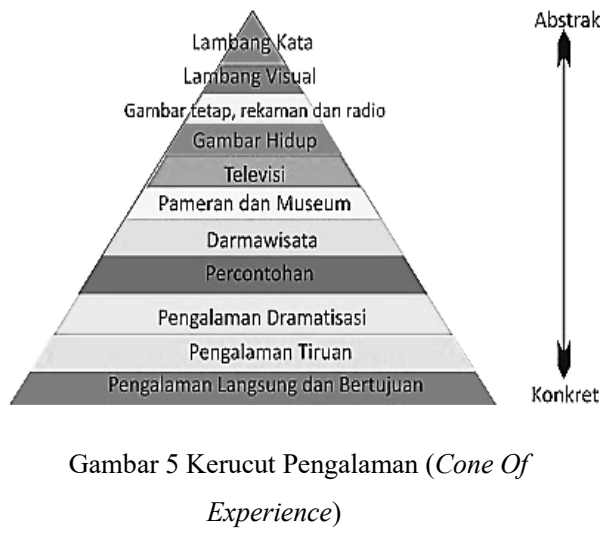

Berdasarkan pendapat para ahli di atas, dapat disimpulkan bahwa media pembelajaran adalah sarana pendidikan yang dapat digunakan sebagai perantara dalam proses pembelajaran untuk mempertinggi efektifitas dan efesiensi dalam mencapai tujuan pengajaran. Ada empat substansi media pembelajaran secara umum, yaitu bentuk saluran, jenis komponen dalam lingkungan pembelajar, bentuk alat fisik, dan bentuk-bentuk komunikasi.

Adapun tujuan media pembelajaran sebagai alat bantu pembelajaran, yaitu mempermudah proses pembelajaran di kelas, meningkatkan efisiensi proses pembelajaran, menjaga relevansi antara materi 
pembelajaran dengan tujuan belajar, dan membantu konsentrasi pembelajaran dalam proses pembelajaran. Sedangkan manfaat media pembelajaran sebagai alat bantu dalam proses pembelajaran, yaitu pengajaran lebih menarik perhatian pembelajar, bahan pengajaran akan lebih jelas maknanya, metode pembelajaran bervariasi, dan pembelajar lebih banyak melakukan kegiatan belajar. Tidak semua media pembelajaran cocok digunakan dalam proses pembelajaran, untuk itu perlu dilakukan pertimbangan dalam memilih media supaya penggunaan media pembelajaran tersebut benar dan tepat. Adapun media yang dipilih harus disesuaikan dengan tujuan pengajaran, bahan pelajaran, metode mengajar, tersedia alat yang dibutuhkan, pribadi pengajar, minat dan kemampuan pembelajar, dan situasi pengajaran yang sedang berlangsung.

\section{- MERANCANG DAN MENGEMBANGKAN EVALUASI FORMATIF.}

Dilakukan melalui kegiatan (a) Peserta didik diberi kesempatan untuk mengenal dan menggunakan media pembelajaran yang menarik berbagai macam bentuk bangun ruang sisi datar, (b) Dilakukan melalui kegiatan pengalaman langsung, (c) Pembelajaran motorik halus perabaan kasarhalus, membandingkan antar bangun ruang, pengelompokkan sesuai bentuk dan ukuran, dan (d) Mengunakan metode penemuan terbimbing.

Langkahlangkahnya dalam merancang Peningkatan kognitif adalah (a) Memilih materi bangun ruang sisi datar, (b) Perencanaan Harian (RPPH), (c) Pelaksanaan, (d) Penilaian

\section{- MEREVISI PEMBELAJARAN}

Peserta didik berfikir benda konkret dalam konsep ini. Peserta didik diberikan pembelajaran dengan benda-benda nyata agar peserta didik tidak bingung. Maksudnya adalah agar peserta didik dirangsang untuk berfikir dengan metode pembelajaran yang menggunakan benda nyata sebagai contoh materi-materi pelajaran. Terciptanya pengalaman melalui benda nyata diharapkan anak lebih mengerti maksud dari materimateri yang diajarkan oleh guru.

Media pendidikan merupakan alat yang secara fisik digunakan untuk menyampaikan isi materi pengajaran, agar terciptanya pengalaman melalui benda nyata diharapkan peserta didik lebih mengerti maksud dari materi-materi yang diajarkan oleh guru. Melalui media benda kongrit dan metode penemuan terbimbing diharapkan peserta didik dapat hasil yang diinginkan.

\section{- MERANCANG DAN MENGEMBANGKAN EVALUASI SUMATIF}

\section{INSTRUMEN TES KEMAMPUAN BERPIKIR KRITIS BANGUN RUANG SISI DATAR}

1) Perhatikan gambar kubus ABCD.EFGH disamping. Melalui titik-titik sudutnya ditarik garis diagonal ruang, sehingga berbentuk limas. 


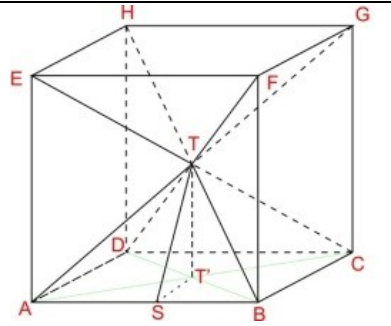

a. Berapa limas yang terbentuk dalam kubus tersebut? Sebutkan.

b. Apakah limas-limas itu kongruen?

c. Berbentuk apakah alas setiap limas itu?

d. Jika panjang rusuk kubus $8 \mathrm{~cm}$, tentukan tinggi limas!

2) Perhatikan gambar balok ABCD.EFGH di atas. Melalui titiktitik sudutnya ditarik bidang diagonal, sehingga berbentuk prisma.

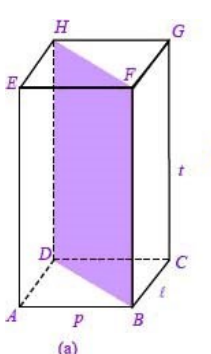

a. Berapa prisma yang terbentuk dalam kubus tersebut? Sebutkan.

b. Apakah prisma-prisma itu kongruen?

c. Berbentuk apakah alas setiap prisma itu?

d. Jika panjang balok $8 \mathrm{~cm}$, lebar balok $6 \mathrm{~cm}$, dan tinggi balok 4 $\mathrm{cm}$. tentukan volume prisma?

3) Sebuah kubus panjang rusuknya 8 $\mathrm{cm}$, memiliki volume sebesar 512 $\mathrm{cm}^{3}$. Jika rusuk kubus diperkecil sebesar $\frac{1}{2}$ kali panjang rusuk semula. Apakah volume kubus baru itu lebih kecil dari volume kubus semula? Beri penjelasan!
4) Jika dikatakan kerucut adalah limas dengan bidang alas berbentuk lingkaran. Selidiki mengapa kerucut bisa dikatakan limas yang alasnya berbentuk lingkaran?

5) Syakir ingin membuat kerangka balok dengan panjang $6 \mathrm{~m}$, lebar $4 \mathrm{~m}$, dan tinggi $2 \mathrm{~m}$. Jika Syakir diberikan kawat sepanjang 100 meter, Syakir dapat membuat kerangka balok lebih dari 3 . Benarkah demikian? Berikan alasannya!

6) Gambarlah balok ABCD.EFGH. Benarkah garis $\mathrm{AB}$ berpotongan dengan garis CD? Beri penjelasan.

7) Jika terdapat miniatur piramida mesir(berbentuk limas persegi) di sekolah, kamu ingin mengecat piramida tersebut(tidak termaksud alas limas) dengan cat berwarna merah, 1 kaleng cat dapat mewarnai $5 \mathrm{~m}^{2}$. Sedangkan volume limas adalah $72 \mathrm{~m}^{3}$, dan tinggi limas $4 \mathrm{~m}$. berapa kaleng catkah yang dibutuhkan untuk mewarnai piramida tersebut?

8) Paman akan membuat etalase toko dari kaca yang terbentuk balok yang berukuran panjang $100 \mathrm{~cm}$, lebar $40 \mathrm{~cm}$, dan tinggi $70 \mathrm{~cm}$, jika harga permeter kaca Rp. 50.000,/meter persegi, hitunglah biaya yang dibutuhkan untuk membuat etalase tersebut? 


\section{KESIMPULAN}

Pembelajaran dengan desain instraksional Dick and Carey diharapkan dapat menjadi lebih menarik dan meyenangkan sehingga dapat mencapai tujuan pembelajaran. Metode penemuan terbimbing dan media benda kongkrit sangat membantu mengarahkan dan merangsang bukan hanya imajenasi peserta didik tetapi juga memberikan pembelajaran langsung bagi siswa. Sehingga pengetahuan yang dihasilkan menjadi lebih nyata dan lebih kongkrit. Kemampuan berpikir kritis sebagai komponen yang sangat mendukung dalam proses pembelajaran adalah kemampuan yang sangat dibutuhkan siswa di masa yang akan datang guna bersaing dimasa depan.

\section{REFERENSI}

Arief dkk. Media Pendidikan. Jakarta: PT raja Grafindo persada, 1996.

Arsyad, Azhar. Media Pembelajaran. Jakarta: Rajawali Pers, 2011.

Dahar, Ratna Wilis. Teori-Teori Belajar dan Pembelajaran. Jakarta: Penerbit Erlangga, 2006.

Damayanti, A., Suradika, A., \& Asmas, B. (2020). Strategi Mengurangi Kejenuhan Anak Dalam Pembelajaran Jarak Jauh (PJJ) melalui Aplikasi ICANDO pada Siswa Kelas I SDN Pondok Pinang 08 Pagi. Seminar Nasional Penelitian LPPM UMJ, 110.

http://jurnal.umj.ac.id/index.php/sem $\underline{\text { nalist }}$
Dick, Walter and Carey, Lou. 2009. The Systematic Design of Instruction. New Jersey: Pearson.

Ismaimuza, Dasa. "Kemampuan Berpikir Kritis Matematis Ditinjau dari Pengetahuan Awal Siswa". Jurnal Pendidikan Matematika, Volume. 2, Januari, 2011.

Johnson, Elaine B. Contextual Teaching \& Learning. Bandung: Kaifa Learning, 2010.

Markaban. Model Pembelajaran Matematika Dengan Pendekatan Penemuan Terbimbing. Yogyakarta: DEPDIKNAS, 2006.

Ruseffendi. Pengajaran Matematika Modern dan Masa Kini. Bandung: Tarsito, 1988.

Sanjaya, Wina. Strategi Pembelajaran Berorientasi Standar Proses Pendidikan. Bandung: Kencana, 2006.

Suradika, A., Winata, W., Wicaksono, D., Hadi, M. S., \& Rifqiyati. (2020). The Influence of Instructional Materials and Educational Background on the Learning Outcomes of Islamic Education. Solid State Technology, 63(6), 1027-1043. http://solidstatetechnology.us/index.p $\mathrm{hp} / \mathrm{JSST} /$ article/view/2185

Suwarma, Dina Mayadiana. Kemampuan Berpikir Kritis Matematika. Jakarta: Cakrawala Maha Karya, 2009.

Yamin, Martinis. Strategi Pembelajaran Berbasis Kompetensi. Jakarta: Gaung Persada Press 2004. 